ISSN: 1231-4005

e-ISSN: $2354-0133$

ICID: 1133180

DOI: $10.5604 / 12314005.1133180$

\title{
ENERGY SAVING SYSTEM FOR OFF-ROAD MACHINES BY THE USE OF THE MOVABLE COUNTERWEIGHT ENERGY RECUPERATION
}

\author{
Artur Gawlik \\ Cracow University of Technology \\ Institute of Machine Design \\ Jana Pawla II Av. 37, 31-864 Cracow, Poland \\ tel.:+4812 6283352,e-mail:agawlik@mech.pk.edu.pl
}

\begin{abstract}
In this paper, concept of energy saving by the use the special recuperation system for hydraulic excavator is studied. This solution is alternative to commercial projects of hybrid systems, which store energy in the hydro pneumatic accumulators or the super capacitors. Suggested solution includes designed system of active counterweight, which cooperates with working mechanism of machine. The hydraulic circuit of active counterweight is connected with the boom standard hydraulic system. The counterweight mechanism is homothetic to working mechanism of the excavator. The homothetic transformation applies to kinematical structure and positions of the centres of gravity. The homothetic transformation provides to static unloading of boom cylinder by the connected counterweight cylinder. The possibility of energy saving by using movable counterweight was estimated during tests. The key parameters of hydraulic system, such as: cylinders velocity, working pressure, oil flow and another were measured on prepared research stand. The comparison of power consumption for standard and modification system during the same work cycles allowed confirms the correctness of the suggested concept for energy saving system. Energy saving ratios for modified hydraulic circuit was calculated for different velocity of boom cylinder and payloads. The active counterweight system for low velocity cylinder of excavator mechanism is ready to application. The hydraulic circuit for higher value of boom cylinder velocity requires resize a few elements for example supply lines.
\end{abstract}

Keywords: active counterweight, excavator, homothetic transformation, energy saving, potential energy recuperation

\section{Introduction}

The energy efficiency and energy saving have become important practical research topics in off-road mobile machinery [2, 6, 7, 9]. Either in order to reduce the energy consumption of the machine, the efficiencies of the combustion engine and components of hydraulic circuit have to be improved or energy that is wasted in the working process should be recuperated by special subsystems. One of the directions of research is energy recovery from swing mechanism of excavator [8]. Komatsu offers a model of excavator with hybrid system. This system converts energy generated when the upper structure is breaking to reduce its speed while turning or to stop it, then stores captured energy in the capacitor, and uses it again to assist the power of the engine via the electric motor when the upper structure is accelerated. Compared with the standard model of hydraulic excavator, the hybrid model achieves about $25 \%$ reduction of fuel consumption. However, this hybrid system based on expensive elements requires service realized by advanced technical staff. In addition, high level of voltage in this circuit creates an additional risk for users. Caterpillar engineers promote other approach to hybrid systems for excavators. In this solution, $98 \%$ of the machine is made from the same components used on standard model of excavator, and the captured energy is stored in piston accumulators. Caterpillar Inc. Company chose the allhydraulic approach because of the high density of hydraulic power. Their system reuses energy via the hydraulic hybrid swing system, which captures the excavator's upper structure swing brake energy in hydro accumulators, and then releases the energy during swing acceleration. This hydraulic hybrid system allows improve fuel efficiency up to 25 percent.

When considering regeneration of energy, the works cycles in which excavator usually operate include repetitive movements of the working links and payload transfers, which provide an 
opportunity for efficient recovery of potential energy [4]. The boom mechanism of these off-road machines may use the potential energy of the working equipment in the lowering phase. Recovered energy can be accumulated in hydro-pneumatic accumulators, but this solution does not allow for a smooth cooperation with the hydraulic system. In particular, the phases of charging and discharging of accumulators require the use of advanced control strategies. The amount of stored energy is strongly dependent on the operating cycle, and should take into account the thermal losses of accumulator in the stop phase.

This study focuses on a solution of energy saving system based on active counterweight. Typical counterweights are assembled quite often in the construction equipment structures but these elements are normally fixed. A counterweight driven by a hydraulic cylinder is used in special machines such as the pipe laying cranes. It is however, only a passive solution, which works apart from the boom mechanism. This system can only increase the static stability of the machine. However, port cranes have movable counterweight, which is permanently driven by the boom mechanism. The counterweight is connected with boom mechanism through a mechanical links. This solution unloads the drive mechanism of crane boom in an approximate manner and increases the stability of the crane. In several projects of the future excavators, movable counterweights are presented. However, this massive element are planned to be moved only in a horizontal plane in order to improve the stability of the excavator during lifting the payload in the bucket.

\section{The design of active counterweight system}

Due to limitations of free space around the excavator cab, it is suggested to make connection of movable counterweight mechanism and working equipment of excavator by the use of hydraulic system. The excavator boom cylinder could collaborate with two units of cylinders, which drive parallel parts of moveable counterweight. The overall assumption was made that presented solution of hydraulic system does not change functional properties of the excavator. To achieve that a few detailed assumptions were made, as: the mass of an active counterweight should not be bigger than the mass of the standard counterweight by reason of additional resistance to the motion of a machine and necessary modification of kinematics pairs, the movable link of the counterweight should not exceed the superstructure contour. These assumptions limits homothetic transformation scale factor to level about $k=0.5$. After an analysis of linkages and fixed counterweights mass for different excavators, it turned out that middle-sized excavators have value of factor the most close to definite factor, which is about 0.9. Due to the dimensions of the original cylinder of Cat 305 machine and dimensions of typical hydraulic cylinders, which could be used in laboratory rig, the scaling factor $k=0.77$ for tested active counterweight system was established.

The shape and dimensions of the mechanism of movable counterweight are the result of the homothetic transformation relative to the excavator mechanism what author described in paper [1] and [3]. The homothetic transformation applies to kinematical structure and positions of centres of gravity. The homothetic transformation provides a static unloading of boom cylinder by the supporting cylinder of counterweight. The correlation between the counterweight centre of a mass and the machine linkage centre of mass could be calculated by a method where components of the centre of the total mass vector are constant s. This situation gives two crucial effects:

- a static overturning moment will be constant for different linkage set up,

- a connection between excavator and counterweight systems enable energy flow between described mechanisms and produces mutually static unloading of working linkages.

It is possible to achieve that only if the counterweight mechanism is homothetic to the linkage mechanism. Fig. 1. presents simplified active counterweight mechanism in relation to typical linkages. First link, which is connected to excavator frame, is a result of homothetic to boom. The second element corresponds to motion of bucket and stick. Taking into consideration the kinematics of excavator links, system where the boom cylinder is connected to the main cylinder of the counterweight should have the greatest effect of energy saving. 


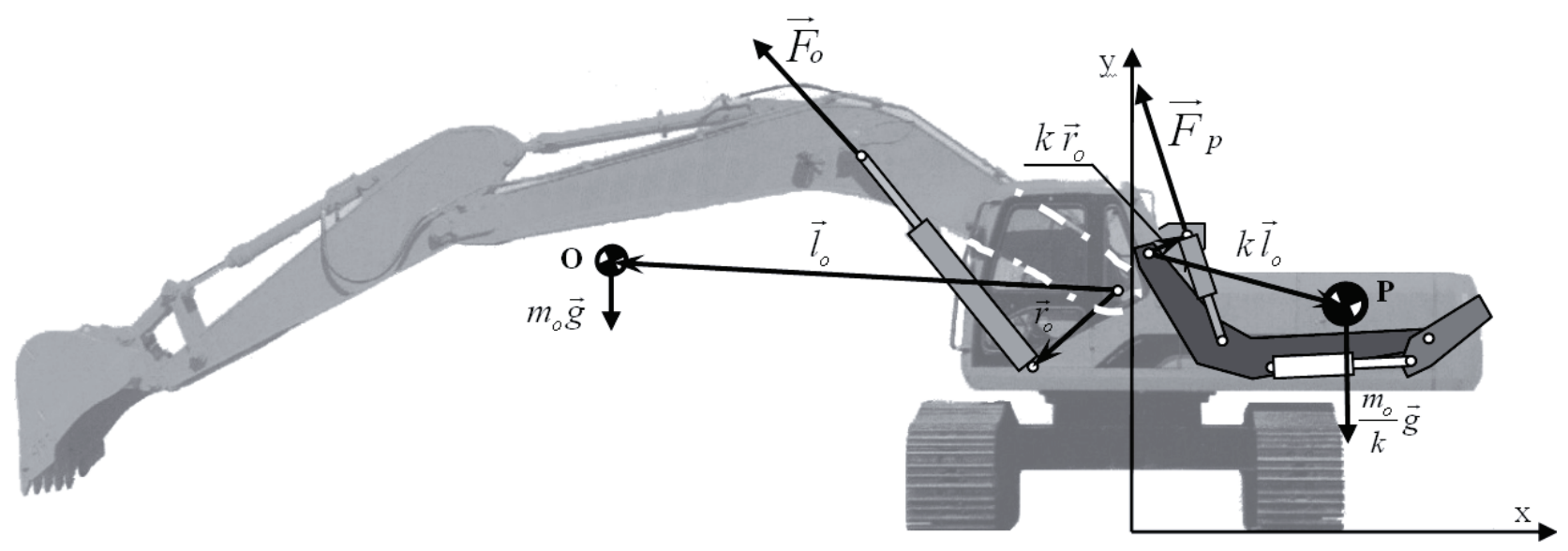

Fig. 1. Structure of excavator with active counterweight

In order to estimate the force $F_{p}$, equilibrium of static moments around the axis of the boom pin of the excavator pin and the axis of the boom pin of movable counterweight was determined.

$$
\begin{gathered}
\mathbf{l}_{o} \times m_{o} \mathbf{g}+\mathbf{r}_{o} \times \mathbf{F}_{o}=\mathbf{0}, \\
-k \mathbf{l}_{o} \times \frac{m_{o}}{k} \mathbf{g}-k \mathbf{r}_{o} \times \mathbf{F}_{p}=\mathbf{0},
\end{gathered}
$$

where: $m_{o}$ - mass of excavator mechanism.

After adding equations (2.1) and (2.2) parties, an equation (2.3) was obtained:

$$
F_{o}=k \cdot F_{p} .
$$

The system of interconnected mechanisms should ensure the velocity of selected points in the ratio $\mathrm{k}$. In a result, a formula (2.4) was calculated:

$$
v_{p}=k \cdot v_{o},
$$

where: $v_{p}$ - velocity of main counterweight cylinder, $v_{o}$ - velocity of boom cylinder

The equation (2.4) allows calculate relation between cross section areas of connected cylinders chambers:

$$
A_{1}=k \cdot A_{4} .
$$

The equation (2.5) determines dimension such as piston diameter and piston rod diameter for main cylinder of counterweight mechanism.

\section{System of moveable counterweight}

The test rig consists of mechanical and hydraulic circuit of mechanism of middle size excavator connected with mechanism of active counterweight. The mechanical part of test stand from original parts of Caterpillar 305 excavator was assembled. This solution has allowed keeping the kinematic structure, which is typical for these kinds of machines. Considering the limited fieldwork in the laboratory, the test rig without bucket mechanism was used. The presented results for configuration of excavator linkages with fixed maximal length of stick cylinder were obtained. Load on the end point of stick was changed from $0 \mathrm{~kg}$ to $80 \mathrm{~kg}$. Lowering phase of boom mechanism was realized without payload but rising phase of this mechanism was performed with $80 \mathrm{~kg}$ of payload. 


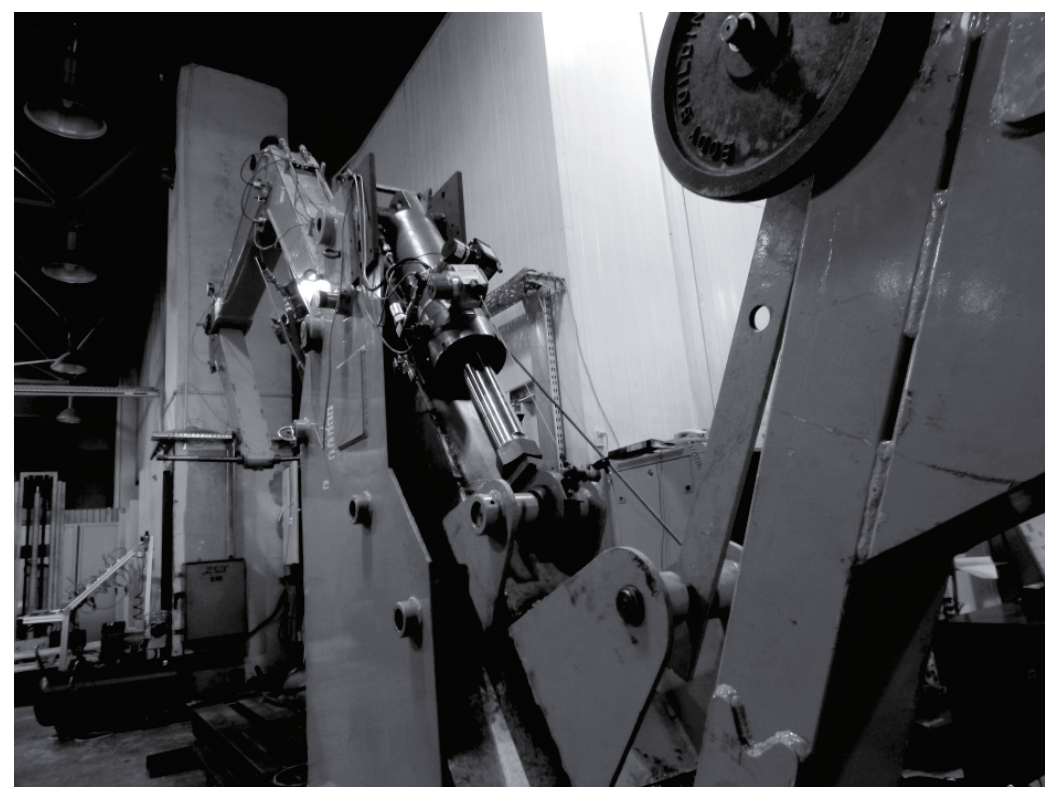

Fig. 2. View of test rig to research of energy recovery system with active counterweight

The mechanism of active counterweight was mounted to the base in such a way as presented in Fig. 2. Therefore, only one cylinder $(140 \times 80 \times 400)$ to drive movable counterweight was used. Due to the total mass of present excavator which was about $358 \mathrm{~kg}$, resulting total mass of counterweight links about $472 \mathrm{~kg}$ for the assumed scale factor $k=0.76$.

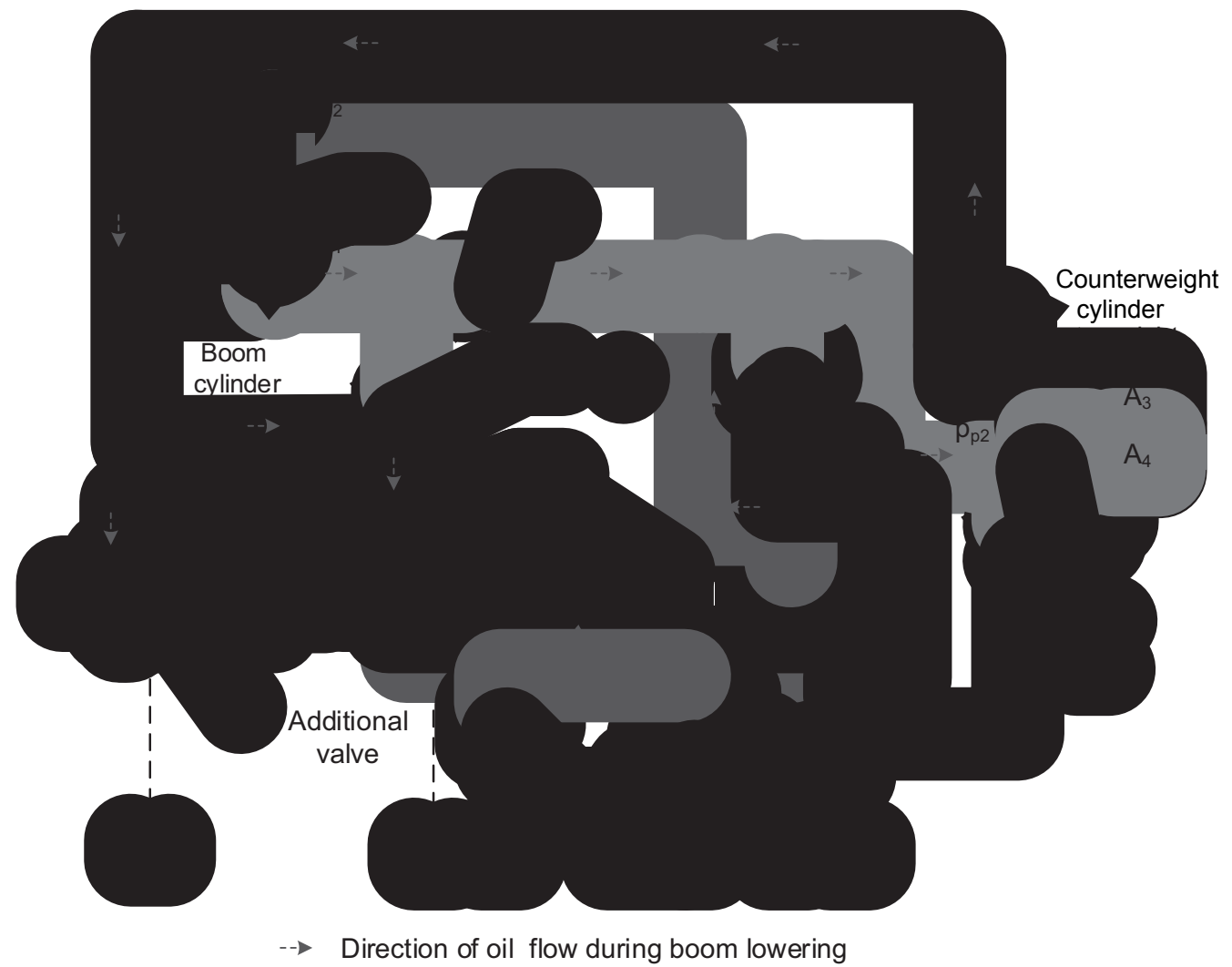

Fig. 3. Scheme of hydraulic system for testing the mechanism with active counterweight: 1 - variable pump PV046_UPG, 2 - relief valve, 3 - distribution valve 4/3-way D3FP, 4 - boom cylinder, 5 - main counterweight cylinder, 6 - closed shut-off valve, 7 -opened shut-off valve

In Fig. 3. main part of hydraulic system for connection between excavator mechanism and active counterweight mechanism is shown. The control strategy with quasi-constant level of working pressure $(10 \mathrm{MPa})$ in the supply line was adopted for the hydraulic pump 1 . Three units of 
Parker D3FP proportional directional control valve 3 were used. This solution gives independent control of each cylinder 4 and 5 power line. These components allow reaching the parameters (pressure, flow) of the hydraulic system similar to those registered on the machine CAT 305 during work on testing ground. Two units of directional valves 3 on the line connecting piston chamber of the counterweight cylinder 5 and pump or tank were used to reduce the drop pressure on those elements for the highest oil flow rates. The setup of the manual shut-off valves 6 and 7 allowed to easily changing the configuration of the hydraulic system to test the excavator mechanism and the same mechanism connected with active counterweight. In Fig. 3 setup of hydraulic elements to test energy saving system during boom, lowering phase is presented.

For comparison of the energy consumption in the standard hydraulic system of excavator and in the hydraulic system, which incorporates the active counterweight, a specific work cycle was adopted to the implementation. From the upper starting position excavator boom was lowered by the use of the boom cylinder, later stopped for few seconds and in next phase (after mounted $80 \mathrm{~kg}$ load to the end of stick) boom was raised back to starting position. A ramp signal to determination actual stroke of the boom cylinder was used. PI controller generated control signal for directional valve. Operation of excavator linkages for three different levels of cylinder velocity during boom raising and lowering was realized.

\section{The comparative tests}

The results of the ordinary excavator system and proposed system of potential energy recuperation were compared from the energy consumption point of view. The same work cycles during comparative tests for both configurations of research stand were realized. Standard excavator system was tested to obtain reference data to comparison them with parameters of active counterweight system. The tests for the three velocity levels of boom cylinder $(0.023,0.045,0.09$ $\mathrm{m} / \mathrm{s}$ ) were carried out. Selected parameters such as pressure, stroke and velocity of the boom cylinder in Fig. 2 are shown. Additionally, the calculated values of flow and hydraulic power $N$ of main cylinders are presented. The inlet power was calculated based on flow rate and pressure in active chamber of cylinders. Active chamber in the cylinder during raising excavator equipment was piston side chamber in cylinder of counterweight mechanism. On the other hand, during lowering the excavator working equipment, piston rod chamber of boom cylinder was an active chamber. Selected parameters for connected mechanisms of excavator and active counterweight are shown in Fig. 4. The results for the lowest and highest values of velocities of boom cylinder that were set during testing are compared in this figure. This allowed showing increasing the pressure drop in the hydraulic line, which connects cooperating cylinders. Fivefold increase in flow resistance (from 0.3 to $1.5 \mathrm{MPa}$ ) has a direct impact on the effectiveness the energy recovery system with active counterweight.

In order to compare the different test setup efficiencies, the energy saving ratio $R_{E}$ was defined:

$$
R_{E}=\frac{E_{S}-E_{R}}{E_{S}} \cdot 100 \%,
$$

where $E_{S}$ is energy consumption of active cylinder chambers without energy recovery and $E_{R}$ is the energy consumption of active cylinders chambers with energy recovery. The ratio $\mathrm{R}_{\mathrm{E}}$ describes how much energy can be saved when energy saving system with movable counterweight is used. The energy consumption for both systems was defined as:

$$
E=\int_{t_{0}}^{t_{1}} N d t
$$

where $\mathrm{N}$ - inlet power for active cylinders chambers. 

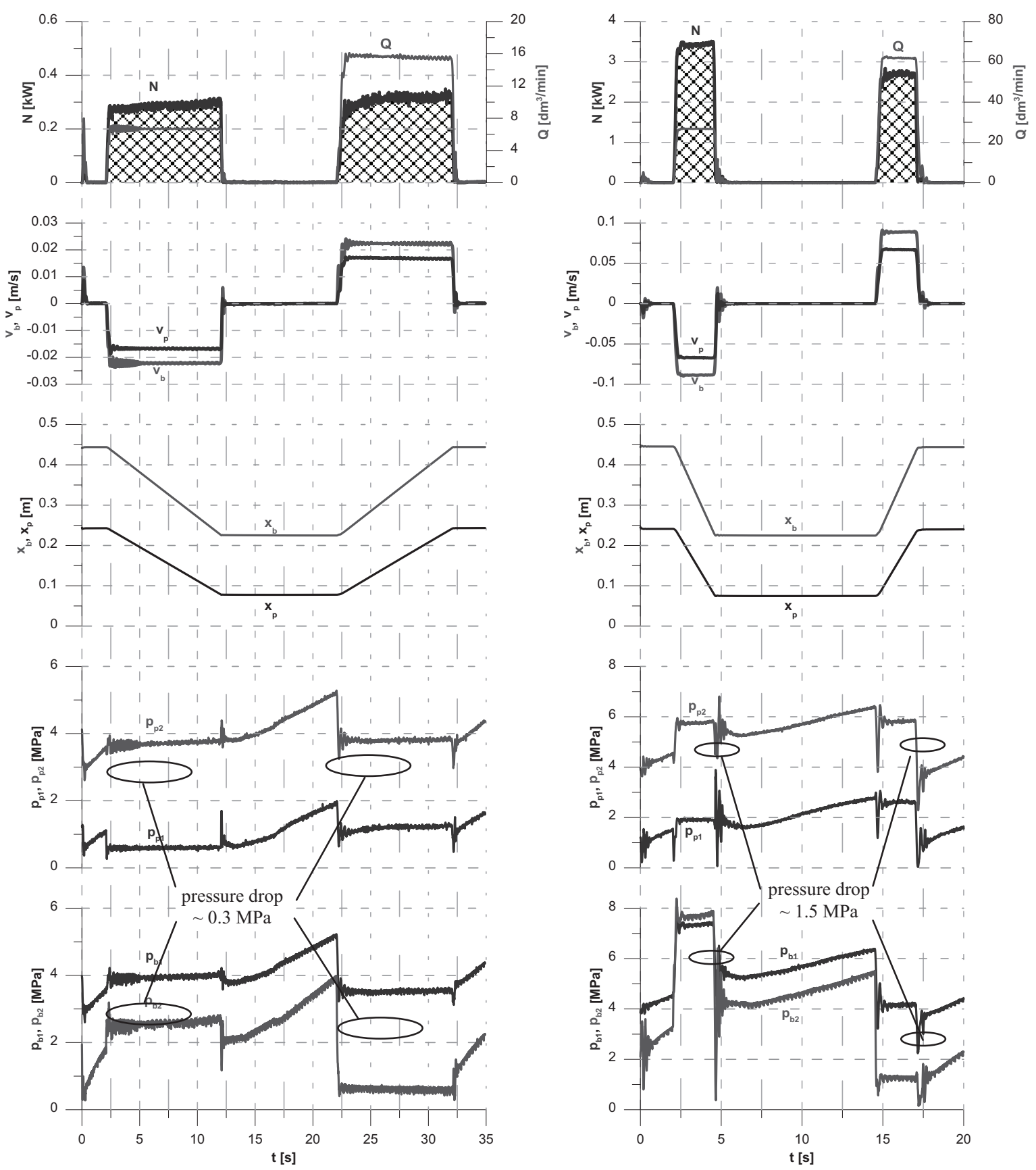

Fig. 4. Selected work parameters of the energy saving system for the lowest (graphs on the right) and the highest (graphs on the left) velocity of boom cylinder witch were set during the tests

In Fig. 5. comparison of inlet hydraulic power as a function of time for both tested systems and boom cylinder velocity about $0.023 \mathrm{~m} / \mathrm{s}$ during cycle is presented. In Fig. 6, similar plots are shown for boom cylinder velocity about $0.09 \mathrm{~m} / \mathrm{s}$ during test. Energy consumption for ordinary and energy saving system was on the same level for values of velocity about $0.023 \mathrm{~m} / \mathrm{s}$ and $0.045 \mathrm{~m} / \mathrm{s}$ (results from this test not presented in this paper) but only during retracting of the boom cylinder. The active counterweight system required more energy than ordinary excavator system in this phase of motion when the velocity of boom cylinder achieved the highest value about 0.09 $\mathrm{m} / \mathrm{s}$. This is due to directly from the increasing flow rate of oil, and thus increased drop pressure in the hydraulic lines and connectors of cylinders. Energy saving in raising phases of excavator mechanism was received. The use of potential energy in the proposed system assisting of excavator drive was reduced of energy demand about $36 \%$ for the boom cylinder velocity about $0.023 \mathrm{~m} / \mathrm{s}$ and $28 \%$ for twice higher the velocity of the cylinder. 


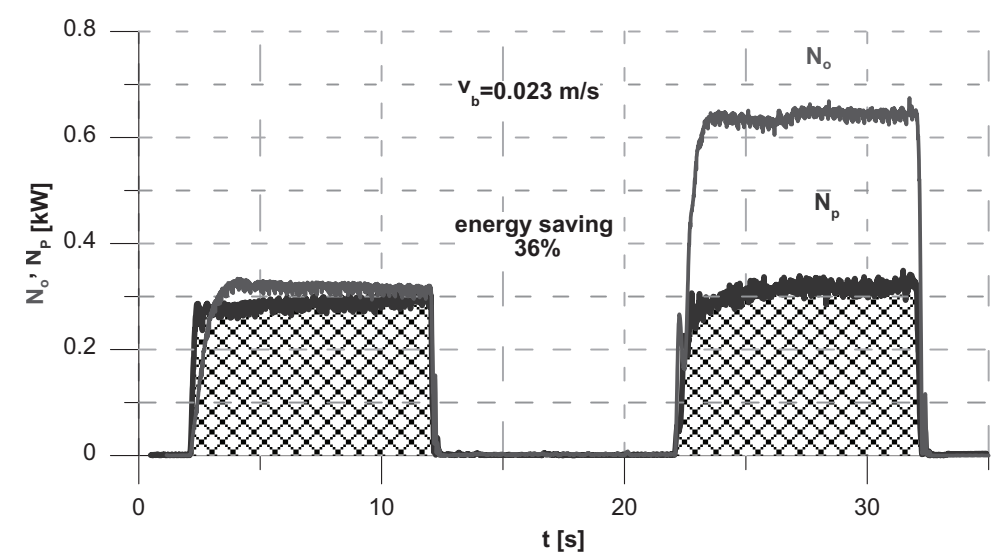

Fig. 5. Calculated energy consumption for the both tested systems with additional load- for velocity of boom cylinder about $0.023 \mathrm{~m} / \mathrm{s}$

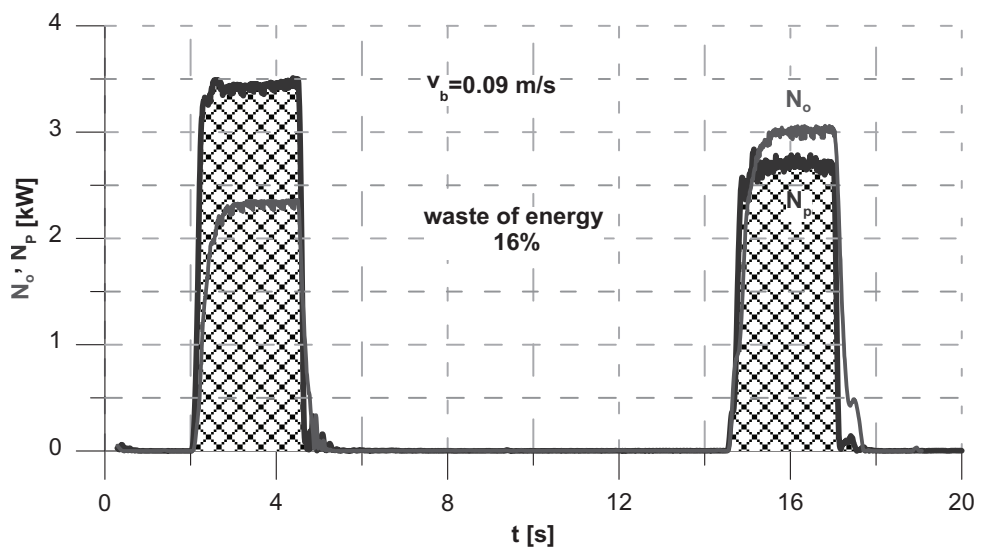

Fig. 6. Calculated energy consumption for the both tested systems with additional load - for velocity of boom cylinder about $0.09 \mathrm{~m} / \mathrm{s}$

For the fixed velocity value of boom cylinder about $0.09[\mathrm{~m} / \mathrm{s}]$, energy losses in the system was observed. The waste of energy was result of the increasing flow resistance in the line between connected chambers of the both cylinders and the valves. The pressure drop was caused by small size of cylinder ports, which also determined the diameter of the hydraulic lines between the connected cylinders.

\section{Conclusion}

Test rig for comparing of hydraulic systems for standard excavator mechanism and mechanism with proposed movable counterweight was performed. The work cycles of excavator mechanism with additional load, about $80 \mathrm{~kg}$ in phase of raising boom were investigated. The tests results confirmed possibility of energy saving (up to $36 \%$ ) by the use of designed and proposed active counterweight energy saving system for excavators. The main portion of saved energy during extension phase of boom cylinder was visible. This ł is positive effect achieved by using potential energy of counterweight mechanism in energy reducing for excavator operation. This energy recuperation system for smaller values of boom cylinder velocity was ready to use without special modifications in the hydraulic circuit on the machine. In order to extend the operating velocity range of the main cylinder of excavator mechanism, for which the active counterweight system will be effective, it is necessary to reduce pressure losses in hydraulic circuit. This requires resizing the diameter of pipes and connectors, especially connectors on cylinders which to be mounted in counterweight mechanism system. However, in the research stand only one cylinder with extra high area of piston and piston rod side was assembled. The commercial version of the system with active counterweight requires two hydraulic cylinders operating simultaneously and 
therefore the hydraulic losses in the connection connectors (at the same flow rate) will be smaller. At this point, it seems important to underline that the scale factor for homothetic transformation of counterweight elements should not differ significantly from the value of 0.5 . For larger values of the coefficient, $k$ dimensions of cylinders chambers are growing and increase of hydraulic losses can be expected. Another way is to minimize the number of hydraulic elements installed between the cooperating cylinders.

The energy recuperation system with the mechanism of the movable counterweight, which is connected directly to the cylinder of the excavator boom, seems to be better than systems based on hydro-pneumatic accumulators. Potential energy of the counterweight is always available to be used and its value does not change with longer phases of machine downtime, what take place in hydro-pneumatic accumulators.

Further research work is oriented for determination of energy saving level for different configurations of excavator mechanism and value of payload. As was assumed the presented hydraulic system does not change the functional properties of the excavator and enables the operator to switch back to standard system when it is necessary (for example while working as a crane).

Tab. 1. List of notations

\begin{tabular}{|l|l|l|}
\hline$x_{b}$ & Displacement of boom cylinder & $\mathrm{m}$ \\
\hline$x_{p}$ & Displacement of active counterweight cylinder & $\mathrm{m}$ \\
\hline$m_{o}, m_{\mathrm{P}}$ & Total mass of excavator and counterweight linkages & $\mathrm{kg}$ \\
\hline$k$ & Scale of homothetic transformation $\left(k=m_{o} / m_{\mathrm{P}}\right)$ & \\
\hline$A_{1}, A_{2}, A_{3}, A_{4}$ & Area of piston and piston rod side of each cylinder & $\mathrm{m}^{2}$ \\
\hline$v_{o}, v_{p}$ & Linear velocity of boom and counterweight cylinder & $\mathrm{m} / \mathrm{s}$ \\
\hline$p_{b 1}, p_{b 2}$ & Pressure in boom cylinder piston and piston rod side & $\mathrm{MPa}$ \\
\hline$p_{p 1}, p_{p 2}$ & Pressure in counterweight cylinder piston and piston rod side & $\mathrm{MPa}$ \\
\hline$Q$ & Volumetric flow rate of oil & $\mathrm{dm} / \mathrm{min}$ \\
\hline$N_{o}, N_{p}$ & Inlet power of in ordinary and active counterweight system & $\mathrm{kW}$ \\
\hline
\end{tabular}

\section{References}

[1] Gawlik, A., Energy recovery system for excavators with movable counterweight, Journal of KONES Powertrain and Transport, Vol. 20, No. 2, pp. 113-120, Warsaw 2013.

[2] Liang, X., Virvalo, T., Energy reutilization and balance analysis in a hydraulic crane, IHA, Tampere University of Technology, 2003.

[3] Michalowski, S., Gawlik, A., Concept of active counterweight system for medium size excavators, Proc. Of 5-th FPNI-Phd Symposium, pp. 462-465, Cracow 2008.

[4] Minav, T., Hanninen, H., Sinkkonen, A., Laurila, L., Electric or hydraulic energy recovery systems in a reach truck - a comparison, Journal of Mechanical Engineering 4, pp. 232-240, 2014.

[5] Ochiai, M., Adaption of hybrid drive in construction machinery and hybrid excavators, Japan Construction Machinery and Construction Association, pp. 35-39, 2009.

[6] Qing, X., Qingfeng, W., Yanting, Z., Control strategies of power system in hybrid hydraulic excavator, Automation in Construction 17, pp. 361-367, 2008.

[7] Sobczyk, A., Improvement of hydraulic system efficiency by means of energy recuperation, Cracow University of Technology, Monograph 403, Cracow 2011.

[8] Tianliang, L., Qingfeng, W., Baozan, H., Wen, G., Development of hybrid powered hydraulic construction machinery, Automation in Construction 19, pp. 11-19, 2010.

[9] Weidong, L., Kaikai, S., Wei, L., Jun, X., Research on potential energy recovery of $16 T$ wheeled hybrid excavator, Second International Conference on Digital Manufacturing and Automation, pp. 996-998, Hunan 2011. 